\title{
Research of post-tensioned concrete composite spans with $\Pi$-beams of road viaduct
}

\author{
Arkadiusz Mordak ${ }^{1, *}$ and Zbigniew Mańko ${ }^{2}$ \\ ${ }^{1}$ Opole University of Technology, Faculty of Civil Engineering and Architecture, Katowicka Street, \\ No. 48, 45-061 Opole, Poland \\ ${ }^{2}$ International University of Logistic and Transport, Soltysowicka Street, No. 19B, 51-168 Wrocław, \\ Poland
}

\begin{abstract}
The paper is presented the results of research conducted on the posttensioned prestressed concrete spans made with precast П-beams of part of seventh spans Eugeniusz Kwiatkowski road viaduct located in Gdynia (between supports no. 97-104) under static field load test. Heavy trucks were used as static loads. Superstructure (main beams), deck slab, and fixed and moving bearings, and also supports (abutment and piers) in both roadways of trestle were tested. Specification and range of conducted research are presented with analysis of results from the tests and calculation, which allowed to the estimate span structures behavior and their actual load-capacity before allow them to normal service on B-class of loads.
\end{abstract}

\section{Introduction}

A subject of a study are post-tensioned concrete spans located between supports 97-104 of the Eugeniusz Kwiatkowski viaduct in Gdynia with continuous-span, precast concrete $\Pi$ beams, of deck type, which were subject to field load tests with the test given load, in the static and dynamic range (Fig. 1). Load carrying structures (main beams), a deck slab, as well as fixed and expansion bearings, supports (abutment and piers) were subject to experimental tests [1].

A purpose of field load testing was to assess the behaviour of spans structure of a part of viaduct under given load, to confirm if assumptions adopted in the load test design were correct, and to determine the actual load-capacity of the structure. It mainly concerned evaluation of actual flexural rigidity of main pre-stressed beams of the load carrying structure, the deck and supports, as well as cross load distribution on individual main beams.

The aim of this study is to present a scope and a course of tests, as well as results of measurements and static strength calculations, with the given load.

Presented initial testing of this structure was performed based on relevant regulations for bridge industry, necessary for obtaining a decision on its put into normal service, meeting at first load-capacity class $\mathrm{C}$, and later class B, in accordance with PN-85/S-10030

\footnotetext{
${ }^{*}$ Corresponding author: $\underline{\text { a.mordak@po.opole.pl }}$
} 


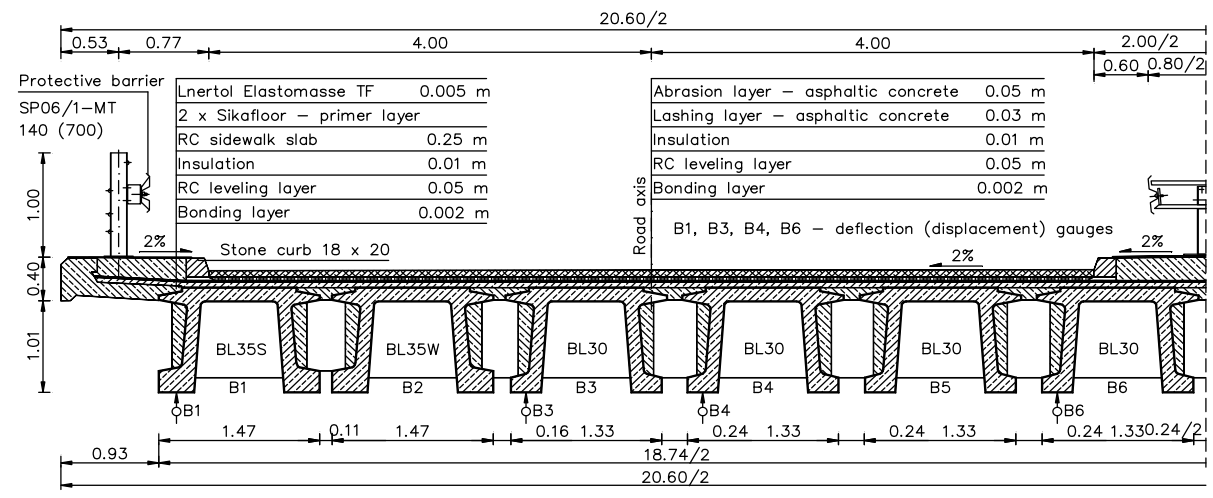

Fig. 1. Cross section of the left part of viaduct structure from the supports number 97 to 104.

standard [2]. Final conclusions presented mainly refer to the quality and load-capacity of the structure, as well as post-erection recommendations connected with its construction and operation [3], [4], [5],[6].

The load test was to demonstrate in particular if and to what extent the elements of spans and the deck slab interact with column supports, i.e. if there were additional loadcapacity extra reserves in structural elements of the viaduct. The extra reserve of the loadcapacity shall be understood here as lower values of deflection and stresses in main beams obtained from measurements in set cross-sections compared to expected, obtained from calculations of agreed and given loading scheme. In the same manner also the correctness of assumptions is checked at a stage of adopting the static load scheme and the computational model of spans structure of the viaduct during its designing [5], [6].

\section{Brief viaduct description}

The tested part of the viaduct (elevated higway) is a seven-span structure, continuous-span type, with the precast beam structure, and theoretical spans of main beams equal to $l_{\mathrm{t}}=$ $23.00 \mathrm{~m}$ each. Spans are supported on pillars and the abutment (Fig. 2). Pillars are made in a form of two reinforced concrete columns with diameter $1.20 \mathrm{~m}$, supported on piles with diameter 1.50 at axial spacing $5.00 \mathrm{~m}$ for each roadway.

Spans of the main viaduct are composite structures of concrete-concrete type, which are made of post-tensioned, prestressed channel beams, $\Pi$ type, rectangular in the plan

a)

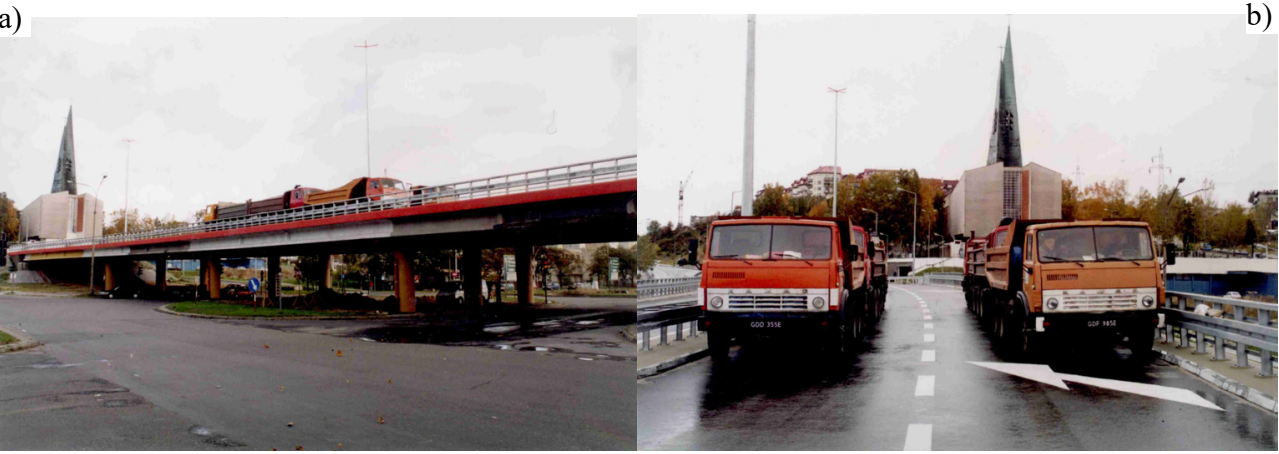

Fig. 2. Testing middle span between supports no 102-103 with arrangement of six loading trucks (S0 loading scheme): a) side view from roadway level under the left roadway of viaduct (visible main beams deflections measurement devices), and b) front view from right viaduct roadway level (in the support no 104 direction). 
view. A half of the span (one roadway), in cross-section, consists of six main beams - two type BL 35S, one type BL $35 \mathrm{~W}$ and three type BL 30 (Fig. 1). The total width of the viaduct is $28.60 \mathrm{~m}$. In both roadways there are roadways made $-10.50 \mathrm{~m}$ wide each, where additionally two roadsides were constructed $-0.60 \mathrm{~m}$ and $0.75 \mathrm{~m}$, as well as a sidewalk 1.80 $\mathrm{m}$ wide. The deck slab is made of a reinforced concrete slab, $0.14 \mathrm{~m}$ thick, that joints individual main beams. The road surface is bituminous, of total thickness $0.14 \mathrm{~m}$ together with insulation of medium thickness $0.01 \mathrm{~m}$. Basic dimensions of the structure are presented in Fig. 1 (the technical design of this viaduct was made by Biuro Projektów Dróg i Mostów in Gdańsk in 1974).

\section{Research scope}

In the frame of experimental tests of spans under the field load static test, measurements [1], [2], [3], [4] were conducted:

- of load-carrying structure deflections in six points located in the middle of individual main beams, measured by means of inductive sensors type W50TS and two accurate levels used for inspection purposes,

- strains (normal stresses indirectly) in main beams and the deck slab in the midspan, which were determined by means electro-resistance strain gauges (and mechanical devices),

- settlement values of fixed and expansion bearings placed on pillars (and the abutment) by means of dial gauges,

- horizontal displacements of expansion bearings in longitudinal direction of spans,

- dimensioning of the structure to check the quality of workmanship of individual elements of spans and supports, as well as to evaluate its technical conditions by overall visual inspection of the structure before, during and after completion of basic experimental testing.

A layout of inductive sensors B1-B12 in the cross-section and along the spans in both roadways of the main elevated highway between supports 101-103 during experimental testing for static loads are shown in Fig. 3-6, and strain gauges T1-T6 in operation [1].

\section{Description of loading trucks}

In a field load test design it was assumed [1] that vehicles to load the structure would be four trucks model TATRA $815 \mathrm{~S}$ of maximum weight up to 26.00 tons and two trucks model KAMAZ 5511 of weight 19.15 tons. The main technical data for both types of vehicles are given in Fig. 3-6, and the length between a front and a rear bumper was 7.040 $\mathrm{m}(7.130 \mathrm{~m})$, load bed width $2.438 \mathrm{~m}(2.500 \mathrm{~m})$, and the spacing of front wheels was 1.989 $\mathrm{m}(1.980 \mathrm{~m})$. The maximum weight of the loaded truck was $260.00 \mathrm{kN}(191.50 \mathrm{kN})$, its

Table 1. Juxtaposition of the axles load in $[\mathrm{kN}]$ of particular loading trucks according to the current weight and catalogs of trucks.

\begin{tabular}{|c|c|c|c|c|c|c|}
\hline \multirow{2}{*}{$\begin{array}{c}\text { Truck } \\
\text { number }\end{array}$} & \multirow{2}{*}{$\begin{array}{l}\text { Registration } \\
\text { number }\end{array}$} & \multirow{2}{*}{$\begin{array}{l}\text { Truck } \\
\text { type }\end{array}$} & \multicolumn{3}{|c|}{ Axles load } & \multirow{2}{*}{$\begin{array}{l}\text { Weight } \\
\text { of truck }\end{array}$} \\
\hline & & & 1 & 2 & 3 & \\
\hline 1 & GDL 192L & \multirow{4}{*}{ TATRA $815 \mathrm{~S}$} & 67,00 & 115,00 & 115,00 & 297,00 \\
\hline 2 & EGB 8321 & & 69,00 & 112,00 & 112,00 & 293,00 \\
\hline 3 & GPD 730E & & 61,00 & 116,00 & 116,00 & 293,00 \\
\hline 4 & GAD 0698 & & 70,00 & 112,00 & 112,00 & 294,00 \\
\hline 5 & GDF 985E & \multirow[t]{2}{*}{ KAMAZ 5511} & 51,00 & 80,00 & 80,00 & 211,00 \\
\hline 6 & GDD 355E & & 50,00 & 78,00 & 78,00 & 206,00 \\
\hline \multirow{2}{*}{\multicolumn{2}{|c|}{ Catalogs of trucks }} & TATRA & 44,70 & 73,40 & 73,40 & 191,50 \\
\hline & & KAMAZ & 60,00 & 100,00 & 100,00 & 260,00 \\
\hline
\end{tabular}


weight without cargo $110.60 \mathrm{kN}(90.00 \mathrm{kN})$, load capacity $149.40 \mathrm{kN}(101.50 \mathrm{kN})$, front axle load $-60.00 \mathrm{kN}(44.70 \mathrm{kN})$, and rear axles load $2 \times 100.00 \mathrm{kN}(2 \times 73.40 \mathrm{kN})$.

Trucks were loaded with sand and weighed directly before tests, and all their axles, as well as the whole vehicle were weighed in sequence. Table 1 presents axle loads of trucks used for load tests according the current weight and the catalogue of vehicles. Arrangement of vehicles on the span was selected in such a manner so that to achieve nearly its maximum effect in places, where measuring points were selected.

\section{Scope and organization of tests}

Tests of that part of the viaduct were executed using two loading schemes S0 and S1 (Fig. 3-6) in three different spans (one placed in the left roadway and two in right roadway). First readings, so-called zero readings at the measuring instruments had been made before the load was placed on the tested span. After the load was placed on the span, further readings were made at all measuring instruments every 10 minutes for a period at least 30 minutes. When the difference between two subsequent readings was higher than $1 \%$ [3], [4] that load had to be kept on the span, as long as that requirement was met. Readings of measuring instruments were performed in a similar way after unloading of the span, i.e.

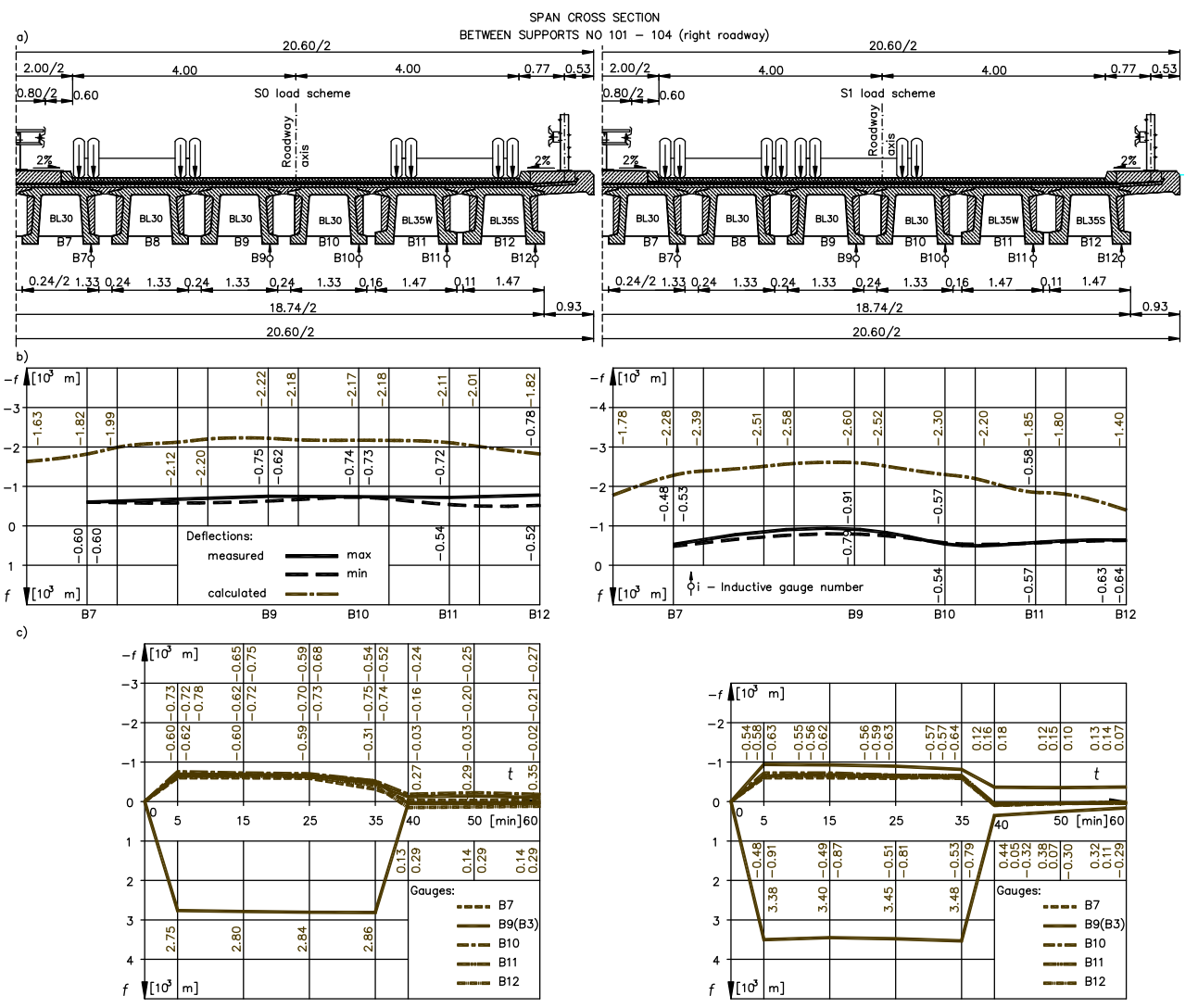

Fig. 3. Test results : a) cross section of right roadway of viaduct between supports 97-104 with deflections inductive gauges, $b$ ) diagrams of maximum (and minimum) measured and calculated deflection values of B1-B6 main beams in span 101-102 cross section, and c) diagrams of deflections variability in time of B1-B6 main beams for two loading case (left column - scheme S0, right column - scheme S1). 
every 10 minutes for the period of 20 minutes. Such readings had to be at least three times. Differences between the last readings at dial gauges or inductive sensors and strain gauges after unloading of the span and the initial values are permanent deflections (strains). Differences between total and permanent deflections (strains) are elastic deflections (strains). Calculated and measured values of deflections (strains) for all loading schemes

a) $\quad 1.2753 .551 .323 .05,3.551,322.601 .32,3.550 .92$ SIDE VIEW

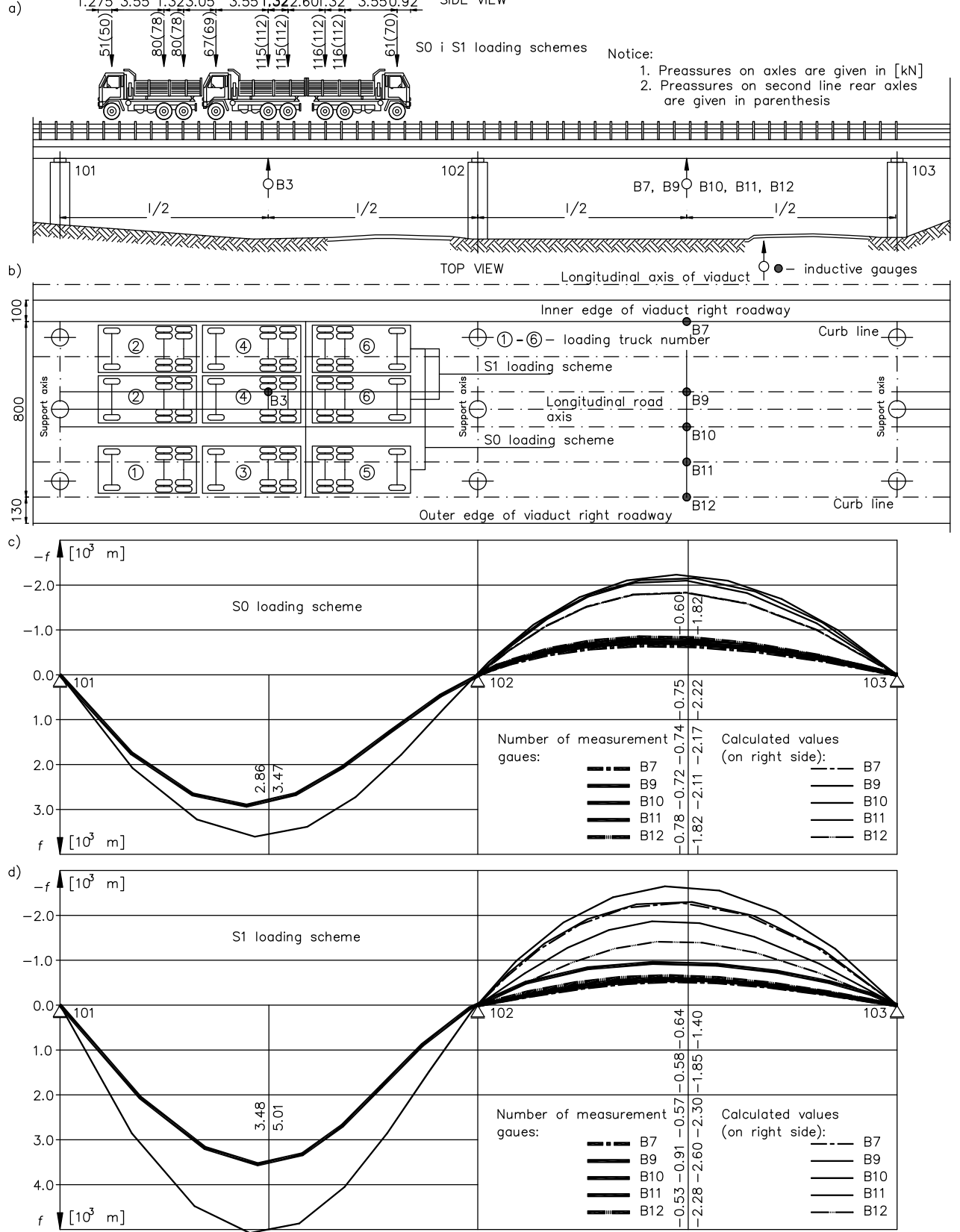

Fig. 4. Test results: a) side view on viaduct testing span between 97-104 supports (right roadway) with B3-B12 deflections inductive gauges arrangement, b) top view on loading trucks arrangement on 101-102 viaduct span, and diagrams of choosen main beams measured and calculated deflections in length of spansfor loading schemes : c) S0 and d) S1. 
are presented in Tables 2-3. Measurements of displacements near bearings were made to explain what the actual settlement values of bearings or cement grout were.

A suitable number of electric cables were prepared and installed for testing, so that measuring instrumentation was placed on the road shoulder, beyond the tested spans, and was additionally covered against possible rain. Instrumentation was placed in the truck parked at the pillar on the roundabout. The weather during tests was good and windless (tests were conducted in morning hours due to the relatively small vehicle traffic in that part of the city).

For measurement of unit strains during testing in scope of static (dead) loads, strain gauges (and also mechanical gauges) were used. After prior surface preparation of span elements to be tested (mechanical cleaning with a grinder and chemical cleaning with acetone or alcohol) frames were stuck in defined places for bases of mechanical gauges or electro-resistance strain gauges. Then a metal rod was slid in those frames, fixed on one side, and on the other, moving side inductive sensors were connected, which measured elongation of the rod. Based on that unit strains in main beams were determined. That type of sensors had the measuring based equal to $1000 \mathrm{~mm}$. Strains were measured on bottom surfaces of the load-bearing structure (main beams and the deck slab). Strain gauges type RL 20/120 were used - manufactured in Poland (Spółdzielnia Pracy Techno-Mechanik w Gdańsku)- suitably aged, to obtain better stability. Gauges had the measuring base equal to $20 \mathrm{~mm}$, resistance $120 \Omega \pm 1 \Omega$ and gauge factor $k=2.15 \pm 0.01$.

Deflection values of selected main beams of the viaduct spans were measured by means of inductive sensors type W50TS connected by means of measuring cables with the UPM60 connector of Hottinger company and a six-channel measuring amplifier type KWS 673.A7, from which the output current signal was directed simultaneously to the input of a multipoint measuring device type UPM60 and to inputs of an eight-channel quick-writing recorder type 330-P/8 Those transducers were placed under the load-bearing structure in the place, where measuring instruments were located.

The inductive displacement transducer type W50TS, with a measuring range $\pm 50 \mathrm{~mm}$, tolerance $\pm 0.02 \%$, consists of a housing with a coil and a moving core led in the casing, pressed by a spring to the outermost position. During measurements, the housing of displacement transducers was fixed in a grip of a magnetic base fixed to a steel stand, steadily lying on the scaffolding (or on the ground), and the core, due to significant height of the structure, was fixed to the steel weight about $6 \mathrm{~kg}$. Before testing, individual measurement chains were calibrated by means of a micrometer spindle. Time of measurements was given from a clock of the multi-point measuring device type UPM60. Measurements release was done automatically in the programmed time interval.

For measurements and monitoring of main beams deflections during tests, also the precise levelling method was used. Levelling was also used to check settlement of the abutment and pillars. For that purpose two precise levelling instruments of Carl Zeiss type Ni 007 with a self-levelling function. The instrument was equipped with a telescope with magnification 31.5 times and an optical micrometer with a plan parallel plate. The measuring range of the micrometer was $5 \mathrm{~mm}$, and the value of each scale interval was equal to $0.1 \mathrm{~mm}$. The scale is adapted to half a centimetre divided levelling rods. The estimated accuracy of reading on the micrometer scale was 0.1 of the unit scale interval. As the accuracy practical for reading of the point directly observed, a three times value of the theoretical accuracy was adopted, i.e. from 0.1 to $0.2 \mathrm{~mm}$ in favourable weather conditions.

Elimination of the impact of weather conditions changes (mainly the temperature) was obtained by application of compensation strain gauges in all measuring points. For sticking of strain gauges, due to possible changes of weather conditions, a special, quick-drying, synthetic resin based glue was used, and the sensors stuck were additionally coated with a protective compound, resistant to impact of weather and mechanical factors. Strain gauges 


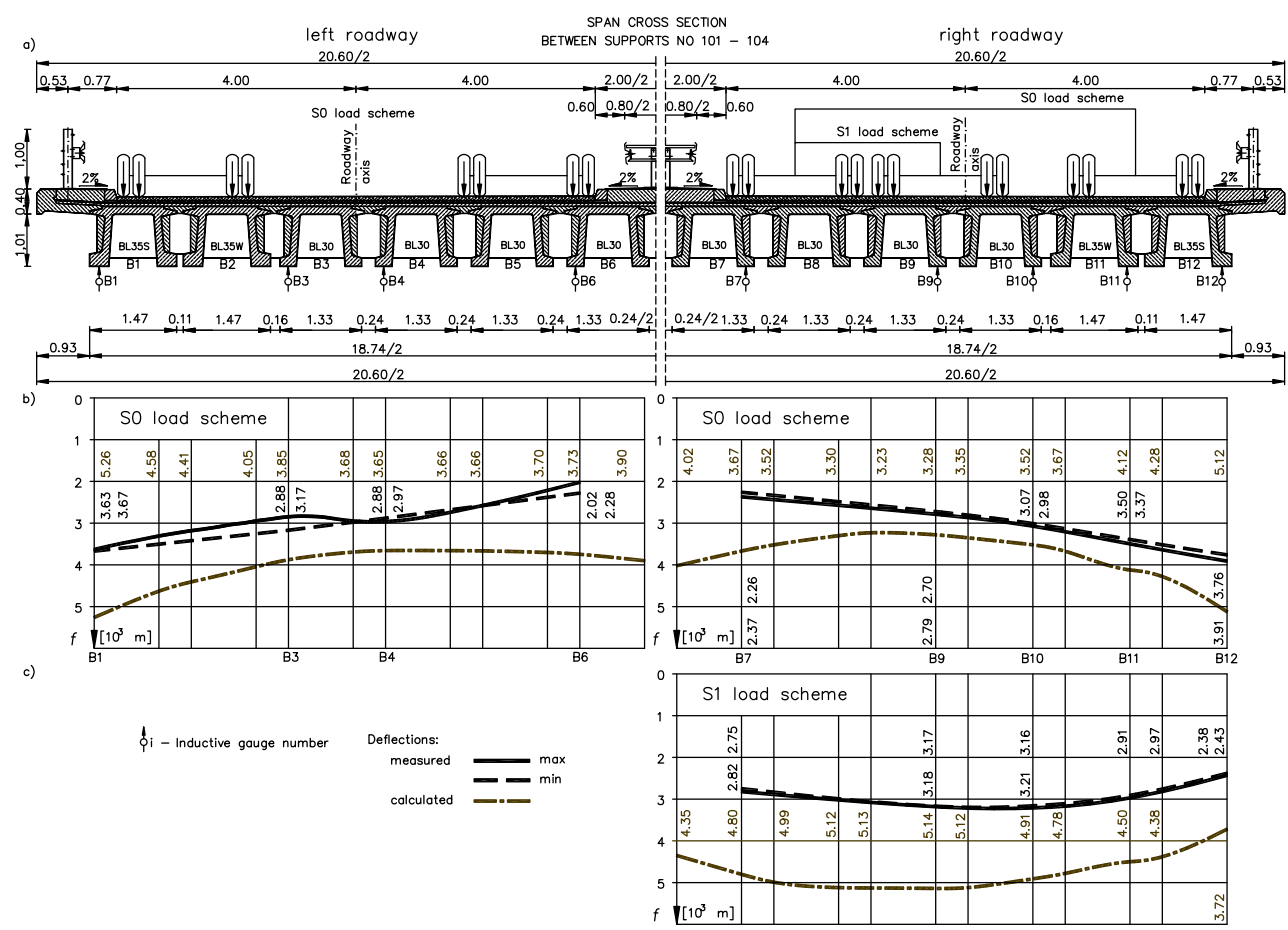

Fig. 5. Test results : a) midspan cross section of viaduct between supports 97-104 - left roadway (left column) and right roadway (right column) with deflections inductive gauges arrangement, b) diagrams of maximum (and minimum) measured and calculated deflection values of B1-B12 main beams in span 102-103 cross section for S0 loading scheme, and c) diagrams of maximum (and minimum) measured and calculated deflection values of B7-B12 main beams in span 102-103 cross section for S1 loading scheme.

stuck on were connected in half-bridge systems with compensation strain gauges, located on steel plates put against the structure, next to the active strain gauge. Half-bridge measuring systems were connected by means of shielded measuring cables with a measuring set composed of channels switches UMK-10 and a digital strain meter DMD 20A type.

\section{Results of main beams deflections obtained from research and calculations}

Measured values of deflections of selected main beams in three tested spans of the viaduct, between supports 97-104 are presented in Fig. 3-6 for two loading schemes considered, and summarized in Tables 2-3. Two loading schemes were performed in each of spans 101-102 and 102-103 in the right roadway and one in span 102-103 in the left roadway (Fig. 3-6). Exemplary diagrams of main beams deflections variability in time are shown in Fig. 3, and diagrams of tested values in longitudinal direction are shown in Fig. 4 and 6.

Horizontal and vertical displacements of expansion and fixed bearings under the main beam B1 (left roadway) and B6 (right roadway) at the abutment from 104 support side, as well as results of unit strains measurements in selected cross-sections of main beams B1B6 in the tested span 102-103 in the right roadway, from two loading schemes S0 and S1 were included in the study [1]. 
Calculations of all geometrical characteristics of main beams were made by means of Auto CAD software, by introducing dimensions of spans and other additional elements, in line with the actual state. Then they were used to describe a computational model in

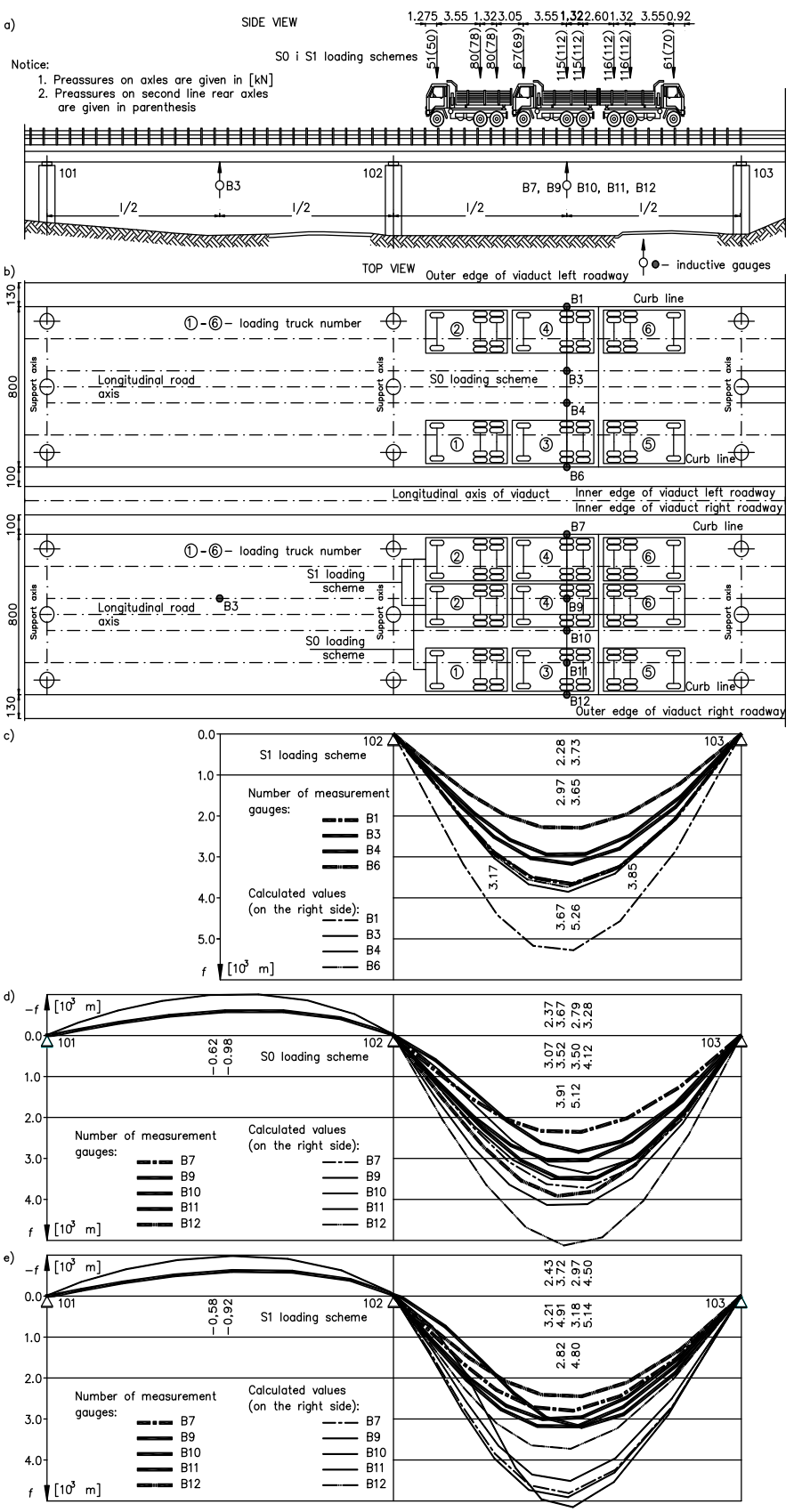

Fig. 6. Test results: a) side view on viaduct testing span between 97-104 supports (right and left roadway) with B3-B12 deflections inductive gauges arrangement, b) top view on loading trucks arrangement on 102-103 viaduct span, and diagrams of choosen main beams measured and calculated deflections in length of spansfor loading schemes : c) S1 (left roadway), d) S0 (left roadway) and e) S1 (left roadway). 
Table 2. Comparison and analysis of measured and calculated main beams deflections in $\left[10^{-3} \mathrm{~m}\right]$ obtained at midspan 101-102 and 102-103 (right roadway of viaduct) for two loading cases

(schemes) S0 and S1.

\begin{tabular}{|c|c|c|c|c|c|c|c|c|c|c|c|c|}
\hline \multirow[b]{2}{*}{ Deflections } & \multicolumn{6}{|c|}{ S0 loading scheme (101-102 span) } & \multicolumn{6}{|c|}{ S1 loading scheme (101-102 span) } \\
\hline & \multicolumn{6}{|c|}{ Main beam (gauge) number } & \multicolumn{6}{|c|}{ Main beam (gauge) number } \\
\hline measured: & B3 & B7 & B9 & B10 & B11 & B12 & B3 & B7 & B9 & B10 & B11 & B12 \\
\hline total $\quad f_{\mathrm{c}}$ & 2,86 & $-0,60$ & $-0,75$ & $-0,74$ & $-0,72$ & $-0,78$ & 3,48 & $-0,53$ & $-0,91$ & $-0,57$ & $-0,58$ & $-0,64$ \\
\hline elastic & 3,71 & $-0,62$ & $-0,96$ & $-0,88$ & $-0,99$ & $-1,07$ & 3,16 & $-0,64$ & $-0,62$ & $-0,70$ & $-0,72$ & $-0,71$ \\
\hline permanent $f_{\mathrm{t}}$ & $-0,85$ & 0,02 & 0,21 & 0,14 & 0,27 & 0,29 & 0,32 & 0,11 & $-0,29$ & 0,13 & 0,14 & 0,07 \\
\hline calculated $f_{\mathrm{o}}$ & 3,47 & $-1,82$ & $-2,22$ & $-2,17$ & $-2,11$ & $-1,82$ & 5,01 & $-2,28$ & $-2,60$ & $-2,30$ & $-1,85$ & $-1,40$ \\
\hline$f_{\mathrm{c}} / f_{\mathrm{o}}$ & 1,0692 & 0,3407 & $-0,432$ & 0,4055 & 0,4692 & 0,5879 & 0,6946 & 0,2807 & 0,3500 & 0,3043 & 0,3892 & 0,5071 \\
\hline
\end{tabular}

\begin{tabular}{|c|c|c|c|c|c|c|c|c|c|c|c|c|}
\hline Deflections & \multicolumn{6}{|c|}{ S0 loading scheme (102-103 span) } & \multicolumn{6}{|c|}{ S1 loading scheme (102-103 span) } \\
\hline measured: & B3 & B7 & B9 & B10 & B11 & B12 & B3 & B7 & B9 & B10 & B11 & B12 \\
\hline total & $-0,62$ & 2,37 & 2,79 & 3,07 & 3,50 & & $-0,58$ & 2,82 & 3,18 & 3,21 & 2,97 & \\
\hline elastic & $-0,61$ & 2,35 & 2,81 & 2,96 & 3,37 & 3,89 & $-0,57$ & 2,82 & 3,38 & 3,54 & 3,04 & 2,49 \\
\hline permanent $f_{\mathrm{t}}$ & $-0,01$ & 0,02 & $-0,02$ & 0,11 & 0,13 & 0,02 & $-0,01$ & 0,00 & $-0,20$ & $-0,33$ & $-0,07$ & $-0,06$ \\
\hline calcul & $-0,98$ & 3,67 & 3,28 & 3,52 & 4,12 & 5,12 & $-0,92$ & 4,80 & 5,14 & 4,91 & 4,50 & 3,72 \\
\hline$f_{\mathrm{c}} / f_{\mathrm{o}}$ & 0,633 & 0,646 & 0,857 & 0,872 & 0,850 & 0,764 & 0,630 & 0,586 & 0,658 & 0,721 & 0,676 & 0,669 \\
\hline
\end{tabular}

COSMOS/M software, which was used to calculate expected values of deflections and unit strains for selected elements of span structure in both roadways of the main elevated highway, from actual distribution of forces and real individual axle loads of trucks from both executed loading schemes - S0 and S1 (Table 1).

Also static values were determined in all characteristic cross-sections of main beams on the length of spans. The following values were analysed:

- displacements of load- structure nodes (main beams deflections),

- internal forces in elements,

- vertical reactions on supports.

Results of main beams deflections obtained from calculations in the midspan of main viaduct spans between supports 101-103 in its both roadways are summarized in Tables 2 3 and in Fig. 3-6.

\section{Tests results analysis}

A requirement for standard evaluation of field load test results in accordance with applicable regulations and standards [2], [3], [4], [5], [6], is as follows:

- calculated and measured values of deflections and unit strains shall be close to each other, - structures of spans and supports shall become elastically deformed within the range of permitted displacements, from loads very close to standard loads, and they shall not exceed values of deflections calculated theoretically,

- permanent deflections shall be no more than $20 \%$ of elastic deflections,

- in result of testing under the field load test, any damages of structural elements of spans or their connections shall not occur.

The analysis of deflection results for selected main beams calculated theoretically and obtained from measurements during tests for spans 101-102 and 102-103 in the right roadway from two loading schemes S0 and S1 is made in Table 2, and for span $102-103$ in the right roadway from S0 loading scheme in Table 3.

Table 3. Juxtaposition and analysis of measured and calculated main beams deflections in $\left[10^{-3} \mathrm{~m}\right]$ obtained at midspan 102-103 (left roadway of viaduct) for loading case (scheme) S0.

\begin{tabular}{|l|c|c|c|c|}
\hline Deflections & \multicolumn{4}{|c|}{ S0 loading scheme (102-103 span) } \\
\hline Measured : & B1 & B3 & B4 & B6 \\
\hline total $\quad f_{\mathrm{c}}$ & 3,67 & 3,17 & 2,97 & 2,28 \\
\hline elastic $\quad f_{\mathrm{s}}$ & 3,71 & 3,24 & 3,06 & 2,52 \\
\hline permanent $f_{\mathrm{t}}$ & $-0,04$ & $-0,07$ & $-0,09$ & $-0,24$ \\
\hline calculated $f_{\mathrm{o}}$ & 5,26 & 3,85 & 3,65 & 3,73 \\
\hline$f_{\mathrm{c}} f_{\mathrm{o}}$ & 0,698 & 0,823 & 0,814 & 0,611 \\
\hline
\end{tabular}


Measurement results of main beams deflection and strains on bottom flanges of selected beams, as well as in the deck slab elements, produced by static field load tests had an elastic character and in case of considered spans were mainly lower than expected values calculated theoretically (by demonstrating at the same time a very high compliance with results of calculations) and than limit deflections $\left(f_{\text {limit }}=l_{\mathrm{t}} / 800=23.00 / 800=28.75 \times 10^{-3} \mathrm{~m}\right.$ [3], [4]) - and they fluctuated from 0.6113 to 0.8234 for the left roadway (Table 3 ) and from 0.2807 to 0,8567 for the right roadway (Table 2), except B3 beam, for which a ratio of deflection values measured to values calculated was 1.0692 from S0 loading scheme.

After the analysis of obtained results of measurements and calculations, it could be concluded that the longitudinal rigidity of spans was sufficient and anchoring of bearings on supports correct. Extra reserves of load-capacity in measured deflections proved suitable rigidity of individual main beams and their good interaction with the composite reinforced concrete deck slab and with the road surface layers.

As far as settlement of bearings on supports are concerned, they were insignificant and they resulted from inaccuracy of readings or errors of measuring instruments, or unevenness of contacting plates in bearings rather than settlement of cement grouts themselves. It was found that settlement values were so marginal, that their impact on other deflection values of main beams were omitted in the analysis of results, especially due to quite significant reserves that occurred. Permanent deflections of individual main beams slightly differed among themselves and they were not proportional to elastic deflections and they did not exceed limit values [3], [4], [5], [6].

\section{Final conclusions}

Practical experience from performed tests under static load, as well as observations of the span structures between supports 97-104 of the main viaduct work, made during tests, and also the comprehensive analysis of results and findings obtained from measurements and their comparison with calculated values allow to formulate conclusions regarding the actual operation of spans of the general nature:

1. Structures of spans composed of main beams of the channel type did not raise any objections for values of cross forces and displacements obtained from calculations and testing. Values of deflections (and normal stresses) of main beams obtained from measurements, did not give any reasons to raise objections regarding their strength and load-capacity in spans, as well as for operation and behaviour of the entire structure, as after consideration of strains and displacements of bearings, they appeared to be much lower than expected values, calculated theoretically (Tables 2-3) for loading schemes and from limit (permissible) values [4].

2. Deflection of main beams had in general elastic character. Minimum permanent displacements found were partly permanent deflections of main beams and they partly came from errors of readings and errors of measuring instruments. A very high compliance of main beams deflections was obtained in tested cross-sections for all considered loading schemes. It indicates on one hand that the assumptions adopted for static strength calculations of these spans were correct, i.e. the compliance of the adopted computational model for the span structure of this viaduct with its actual operation, on the other hand obtained results are a signal that their structures still have simply extra reserves of loadcapacity, and the beams were shaped in an optimum manner (these conclusions are also fully confirmed by the analysis of strains and normal stresses in the main beams calculated based on these strain values).

3. Mean values of deflections, unit strains (normal stresses) in main beams, obtained from measurements in majority of considered cross-sections, lower than calculated values corresponding to them, prove the rigidity of spans closer to values assumed in calculations, 
and that is probably due to interaction of the reinforced concrete deck slab with main beams, as well as layers of the road surface. With consideration of bearings settlement and permanent deflection of main beams, i.e. if we treat the deflections measured as total elastic deflections, corresponding ratios will increase in favour of the structure safety.

4. Elements, which are deemed the most effort elements of the spans structure that require further detailed testing and analyses, are elements of the deck slab, where all stresses from their direct load with truck wheels are added up to stresses from their interaction with main beams. Results obtained based on measurements of normal stresses in the slab and their analysis demonstrate a very high impact of traditional deck slab interaction with main beams due to their direct connection, which was not taken into account in static calculations.

5. Based on tests performed for this fragment of the main viaduct between supports 97104 in range of static loads, it can be released for dynamic tests [1] and then to its normal use under load according to class B [2].

\section{References}

1. Z. Mańko, B. Stankiewicz, A. Mordak: Static field load tests of E. Kwiatkowski viaduct spans in Gdynia. Scientific-Research Center for the Development of Bridge Industry MOSTAR, Wrocław, Poland, December 1998.

2. PN-85/S-10030.: Bridge objects. Loads. (polish standard)

3. PN-91/S-10042.: Bridge objects. Concrete, reinforced concrete and prestressed structures. Designing. (polish standard)

4. PN-S-10040:1999.: Bridge objects. Concrete, reinforced concrete and prestressed structures. Designing. Requirements and testing. (polish standard)

5. Regulation of the Minister of Transport and Maritime Economy of May $30^{\text {th }} 2000$ on technical conditions to be met by road engineering facilities and their location.

6. Recommendations regarding the quality of in-situ concrete in newly built bridge structures. Road and Bridge Research Institute, Wrocław, Poland. 